SIR,-Despite the considerable interest and imaginative investigations being carried out into the sudden infant death syndrome little or no attention seems to have been paid to the precarious limitations of air flow present in children during the period of greatest risk of a cot death.

All mammalian neonates drink milk and have an intranarial epiglottis. The larynx is both the narrowest and possibly the most vulnerable part of the upper airway in these babies. R Pracy and I, after examining the histological structure of over 100 larynges from babies of a wide variety of species including many primates, have shown that the supraglottis is largely composed of glandular tissue, which is also present in the subglottis and upper trachea (unpublished data). In humans there is a reduction in area from the glottis to the subglottis - on average in a 3 month old baby from $9.3 \mathrm{~mm}^{2}$ to $7.0 \mathrm{~mm}^{2}$, increasing to $8.5 \mathrm{~mm}^{2}$ for the upper trachea. The subglottic subepithelial region is rich in glands, and any increase in thickness secondary to infection when combined with increased viscosity of secretions might seriously impair air flow. Further examination of the larynges from babies who have died from the sudden infant death syndrome is progressing, for routine macroscopical examination is unlikely to show these changes or permit measurements of the area subtended by vocal cords or subglottis.

Humans are the only primates that leave their young unattended in a supine or prone position. This may explain the apparent absence of this syndrome in other species despite similar restrictions within the laryngeal complex - for example, common marmoset, glottis $4.3 \mathrm{~mm}^{2}$, subglottis $3.2 \mathrm{~mm}^{2}$, and upper trachea $7.5 \mathrm{~mm}^{2}$; and sooty mangaby, glottis $3.9 \mathrm{~mm}^{2}$, subglottis $2.8 \mathrm{~mm}^{2}$, and upper trachea $6.7 \mathrm{~mm}^{2}$.

Though not necessarily indicating ways of avoiding this tragic condition, examining the detailed morphology and histology of this vital part of the respiratory system may offer a more rational explanation of the aetiology of some cases of the sudden infant death syndrome than has hitherto been possible.

D F N HARRISON

Institute of Laryngology and Otology,

London WCIX 8EE

SIR,-As an orthopaedic surgeon with a special interest in paediatric orthopaedics and an interest in spinal surgery I have spent much time persuading parents that the prone position has advantages for neonates.

Professor A D Milner and Dr N Ruggins reached the balanced conclusion that we have "not yet reached the point" where we should recommend the supine or lateral position rather than the prone.'

Though it is well known that the general advantages of the prone position include a decreased risk of aspiration, an improved gastric emptying time, and improved respiratory function, the orthopaedic advantages of the prone position are perhaps a little less known. Generally, this position eliminates the potential lateralising effect of gravity and also encourages the development of the neck muscles, therefore enhancing head control. If placed in the supine position babies tend to turn towards the right side ${ }^{2}$ so that gravity can exert similar forces as in the lateral position. In more specific terms, the prone position prevents the development of progressive infantile idiopathic scoliosis with its potentially crippling consequences $^{3}$; postnatal moulding syndromesfor example, plagiocephaly ${ }^{3}$; and limited hip abduction, which may occur in $9 \%$ of babies who are nursed supine or on their sides. ${ }^{+}$The prone position is not, however, a prophylactic measure against congenital dislocation of the hip.

Clearly, the only way of conclusively investigating the importance of the prone position in the aetiology of the sudden infant death syndrome is to carry out multicentre prospective controlled trials, but until this is done the best evidence that the prone position is not harmful comes from Sweden (K Palmén, personal communication). In 1976 the prone position was recommended for all neonates, ${ }^{2}$ and a $90 \%$ acceptance rate was achieved; before this it had been customary for babies to be nursed supine. The incidence of the sudden infant death syndrome remained low at about 0.9 per 1000 and showed no real increase.

I therefore agree that present knowledge is such that neonates should not be deprived of the possible advantages of the prone position.

DAI ANTHONY JONES

Morriston Hospital

Swansea SA6 6NL

1 Milner AD, Ruggins N Sudden infant death syndrome. Br Med f 1989;298:689-90. (18 March.)

2 Mau H. Aetiology of idiopathic scoliosis. Reconstr Surg Traumatol 1972;13:184-90

3 McMaster MJ. Infantile idiopathic scoliosis: can it be prevented? f Bone foint Surg $[\mathrm{Br}]$ 1983;65:612-7.

4 Palmén K. Prevention of congenital dislocation of the hip. Acta Orthop Scand [Suppl] 1984;208:1-107.

SIR, - I have long maintained that the safest sleeping position for young babies is on one or other side with the head of the cot raised so that the head is higher than the body. Therefore the finding of a threefold increase in sudden infant deaths in Holland after the practice of nursing babies prone became widespread ${ }^{1}$ is of considerable interest. As in most discussions on sleeping position and the sudden infant death syndrome, however, the most important point has surely been missed.

Gastro-oesophageal reflux is undoubtedly only one of many causes, while one sleeping position may be better than another for more than one reason, but all horizontal positions carry a higher risk of reflux. A useful analogy is an open wine bottle, which readily spills its contents on its side but not with the neck propped. What really matters is not whether the baby sleeps prone or supine but that the head of the cot is raised so that the larynx is higher than the stomach.

Any regurgitation is potentially hazardous. Even a small volume of gastric fluid near the larynx may trigger reflex spasm of the cords and apnoea without any of it being aspirated. Anyone who has ever choked on a drop of water will readily testify what an unpleasant experience this is.

A fundamental characteristic of babies in the vulnerable age group is that they have large liquid feeds, after which they are put down directly and quickly fall asleep. Few adults drink comparable amounts of fluid and promptly doze off prone on a full stomach - and those who try are more than likely to be sick.

All babies regurgitate readily awake and asleep. While the importance of regurgitation in individual cot death victims may be arguable, a high incidence of gastro-oesophageal reflux during sleep has been shown in "near miss" cases using pH probes, barium swallows, and isotope milk scans. ${ }^{23}$ Nursing babies at risk with the head up proved effective, but one baby who had responded well for four months died a week after the parents abandoned positional treatment against medical advice. $^{*}$

All young babies should be nursed with the head raised. Cots should be made with regular inclines of $15-20^{\circ}$ and alternative adjustments instead of vice versa. The tilting facility of the standard hospital maternity cot is so badly designed that it is difficult to achieve the right incline. It is easy enough to prop one end of the cot on books or blocks, but until cots are specifically made with the right slope few parents will take the trouble.

The implication of the Dutch findings is that many babies would not have died if they had not been nursed prone. I believe that nursing babies routinely with the head of the cot slightly raised would substantially reduce gastro-oesophageal reflux during sleep and with it the incidence of cot death.

HERBERT BARRIE

Parkside Hospital,

London SW19

1 de Jonge GA, Engelberts AC, Koomen-Lifting AJM, Kostense PJ. Cot death and prone sleeping position in The Netherlands. Br Med F 1989;298:722. (18 March.)

2 Jeffery HE, Rahilly P, Read DJC. Multiple causes of asphyxia in infants at high risk of suddent infant death. Arch Dis Childhood 1983;58:92-100.

3 Spitzer AR, Boyle JT, Tuchman DN, Fox WW. Awake apnoea associated with gastroesophageal reflux: a specific syndrome. $f$ Pediatr 1984;104:200-5.

4 Herbert JJ, Book LS, Bray PF. Gastroesophageal reflux in the "near miss sudden infant death syndrome." $\mathcal{F}$ Pediatr 1978 92:73-5.

SIR,-Your recent editorial on this topical and distressing event identifies central apnoea and hyperthermia as possible risk factors without attempting to address their adverse circulatory effects.

Normal cyclical inspiration by increasing negative intrathoracic pressure is an important component of the venous pump right atrial filling mechanism, along with the vein massaging effects of leg muscle contractions and competent leg vein valves. Hyperthermia dilates and expands the venous system so that it holds a higher proportion of total blood volume and thus like apnoea has an adverse effect on venous return, reducing right atrial filling and consequently arterial output.

When an unfortunate guardsman standing absolutely still in full ceremonial uniform on a very hot day can faint from cerebral ischaemia caused by venous pump failure it is perhaps not surprising that a swaddled cot infant with the deadly combination of sleep apnoea and hyperthermia may suffer a similar type of cardiac input failure resulting in myocardial ischaemia and cardiac arrest.

In view of the recognition that this sudden death syndrome is less common in Hong Kong and AfroAsian crowded households it should bé possible by respiratory monitoring to discover whether sleep apnoea is indeed lessened in a noisy room. As well as taking precautions to control the infant's body temperature, raising the foot of the cot two or three inches would encourage venous return along the valveless vena cava towards the right heart.

Elie,

THOMAS SEMPLE

Fife KY9 IDN

SIR, - The observations of Dr Natalie N Y Lee and colleagues on cot deaths in Hong Kong ${ }^{1}$ shed some welcome light on the true position there.

On the basis of 16 cases they have shown that the true rate in Hong Kong is $0 \cdot 3 / 1000$ live births (my calculated $95 \%$ confidence interval is 0.15 to 0.45 ) rather than the $0.04 / 1000$ births previously reported. ${ }^{2}$ This rate is still less than one fifth that in the United Kingdom and this might be associated with the habit of placing babies to sleep in the supine position, which is plainly the cultural norm in Hong Kong Chinese families. The association between prone sleeping position and cot deaths is confirmed by Dr de Jonge and his colleagues in their study in The Netherlands ${ }^{3}$ and in many other studies. ${ }^{+}$We have ourselves shown it to be true in the much larger United Kingdom national study of postneonatal mortality. ${ }^{5}$ That there is an association between prone sleeping and cot deaths is indisputable. The question now is whether there is a "causal" connection.

An important question overlooked by Dr Lee and colleagues is: "Why do some Chinese families break an almost universal cultural habit and place their babies prone? Perhaps the question should be: What sort of exceptional characteristics do these 
babies have? Emery has suggested that these babies may have been more likely to have been admitted to a special care baby unit, where they will usually have been placed prone. ${ }^{6} \mathrm{My}$ recently born first child (boy, born in winter, of low birth weight) was placed supine bearing in mind our own work on sleeping position and the risk associated with these other characteristics. A few weeks later, however, he had an acute upper respiratory tract infection which he could sleep through only if placed prone. He has had another infection since then and is currently in the throes of his third. On each occasion he could comfortably sleep only in the prone position and he always sleeps prone now.

I note that the only two control babies in the Hong Kong study who were normally placed supine were in hospital. Is the reason that some Chinese families break an almost universal cultural norm and place their babies prone to do with the fact that those babies have acute upper respiratory tract infections or other conditions which might make sleeping supine difficult-and is this the "cause" of their increased risk of cot death rather than the sleeping position itself?

J P NICHOLL

Medical Care Research Unit,

Sheffield S10 2RX

1 Lee NNY, Chan YF, Davies DP, Lau E, Yip DC. Sudden infant death syndrome in Hong Kong: confirmation of low incidence. death syndrome in Hong Kong: confi
$B r$ Med f 1989;298:721. (18 March.)

Br.Med f 1989;298:721. (18 March.)
Davies DP. Cot deaths in Hong Kong. Lancet 1985;ii: 1346.

3 de Jonge GA, Engelberts AC, Koomen-Liefting AJM, Kostene $\mathrm{PJ}$. Cot death and prone sleeping position in The Netherlands. BrMed f 1989;298:722. (18 March.)

4 Beal SM. Sleeping position and SIDS. Lancet 1988;ii:512.

5 Nicholl JP, O'Cathain A. Sleeping position and SIDS. Lancet 1988;ii: 106

6 Emery JL. Sleeping position, cot mattresses and cot deaths. Lancet 1988;ii:738-9.

\section{Age at death from cystic fibrosis}

SIR, - It is encouraging to see that John R Britton independently confirms recent reports ${ }^{2}$ of the improvements in survival of patients with cystic fibrosis in the United Kingdom in the past 30 years.

The multivariate model that Dr Britton used to determine the independent effects of social class, sex, and region of residence on age at death is however, flawed and thus of limited use; it specifically ignores interaction terms. Thus if the introduction of a specialist clinic in a region is thought to have an important effect on survival in the region this may be examined by the region and year interaction terms. Specialist clinics have been introduced in some regions during the period of the study. If these interaction terms are unimportant for regions with specialist clinics then this would be prima facie evidence that such clinics were not influencing the survival within their region.

A plausible explanation for the Northern region showing the best survival and Wales the worst is that at the beginning of the period Northern region was doing particularly well and Wales very badly, but for more recent times Wales is doing better and Northern not so well. This would show as region/ year interaction in an appropriately formulated model. This explanation is consistent with the data published by Dr Britton and also unpublished data from the British Paediatric Association's cystic fibrosis working party.

Until these interaction terms are shown not to be important there is no reason to believe that the model presented is a reasonable representation of reality; all the estimates are therefore suspect, and the conclusions drawn from them are unsafe.

P A LEWIS

Department of Medical Computing and Statistics, University of Wales College of Medicine, Cardiff CF 4 XN
Britton JR. Effect of social class, sex, and region of residence on age at death from cystic fibrosis. Br.Med $\mathcal{J}$ 1989;298:483-7. (25 February.

2 British Paediatric Association Working Party on Cystic Fibrosis. Cystic fibrosis in the United Kingdom 1977-85: improving picture. BrMed f 1988;297:1599-602.

AUTHOR'S REPLY, - When I analysed the mortality data on cystic fibrosis I looked at the region and year interactions carefully, for the very reasons $\mathrm{Dr}$ Lewis suggests. The necessary breakdown of data by region, sex, social class, and year led to some very small cell frequencies, and I tried to get round this by aggregating data over longer time periods within the 13 year period. Irrespective of the approach used, the region and year interactions in these data were, however, not significant. I therefore elected to exclude the interaction terms from the model and to present the overall ranking of regions for average performance between 1974 and 1986. Naturally, the relative positions of the regions in the ranking would be expected to vary from year to year, but my finding was that the extent of the observed variation with time did not differ more than could reasonably be expected by chance. I do not have the necessary information to categorise regions according to whether or not they introduced specialist clinics during this period and would welcome the opportunity to do so; I fully agree that this may give valuable insight into the impact of the clinics on survival.

Dr Lewis can therefore be reassured that the model presented is perfectly appropriate and that the estimates are reasonable. I hope that his reservations about the practical significance of the regional differences I described do not detract from the main point of my paper, which was to draw attention to the need to control for social class differences when comparing survival between different forms of management. I do not know of any comparison of specialist care versus usual care or large centres versus small centres in which this has been done. That is where the real potential for suspect or unsafe conclusions lies.

Respiratory Medicine Unit,

JOHN BRITTON

City Hospital,

Nottingham NG5 1 PB

\section{Control of hospital infection}

SIR,-Professor Mark Casewell' ${ }^{1}$ and Dr A F M S Rahman $^{2}$ have commented on the important part played by microbiologists in managing infection in hospitals and their potential to contribute to the "new" specialty of public health. Attention has rightly been drawn to their experience in the surveillance, diagnosis, treatment, and control of infection. I would like to make a few observations from a parallel specialty, that of clinical infectious diseases.

Though nowadays used to relying on microbiologists for innovation and quality control in laboratory diagnosis and monitoring of treatment, the clinical specialist in infectious diseases has skills that should not be overlooked. These are particularly important in epidemiology, clinical diagnosis, and medical management. A combination of the first two is invaluable in suspecting and investigating various community acquired diseases. The required degree of skill in taking an epidemiological history and examining for subtly evolving signs takes time to develop. It may not be available to a microbiologist, whose clinical colleagues are practising acute general medicine. Without this database the process of diagnosis and treatment may be appreciably slowed, just as it might be if a microbiologist was unaware of the likely local causes of nosocomial or opportunistic infections in his or her hospital.

Topical examples of this include uncommon diseases, such as rickettsiosis, leptospirosis, and tularaemia, which may be considered only late in the course of investigation unless time and skill can be given to specialist clinical assessment. Other examples, such as poliomyelitis, diphtheria, and anthrax, can cause serious diagnostic difficulty because the wild pathogen is unfamiliar to laboratory workers and may be difficult to distinguish from harmless commensals or vaccine organisms. The clinical diagnosis may be fairly easily confirmed or excluded, however, by an experienced specialist. This is important with a disease with a short incubation period and serious epidemiological consequences. Legionnaires' disease falls into this category; it may be clinically suspected with a high degree of certainty but can defy laboratory confirmation for as long as nine weeks.

All of these examples have been drawn from our experience at this unit last year; many more could be quoted, including enteric fevers, dysenteries, and unusual or partly treated presentations of common diseases. A specialist in infectious diseases also has a broad training in general medical subjects. This enhances experience in distinguishing infections from other causes of fever and from acute surgical conditions, which often mimic acute infections. Rather than a second microbiologist being appointed, a specialist in infectious diseases should be considered to complement microbiological skills. With increasing mechanisation and possibly early privatisation of laboratories it would make more sense to offer clinical training in infectious diseases to senior registrars in microbiology than to turn them hurriedly into substitute public health doctors.

Indeed, it is important to distinguish between infection management and public health. Public health entails population surveillance for changes in demography, patterns of health and disability, education, and needs and attitudes, as well as health care planning, data handling, and incident control. Hastily trained senior registrars in any specialty would hardly be well received by the numerous community, acute, and local authority experts already involved in public health services. It will probably need a senior and established consultant with extensive training to provide successful leadership in a public health post.

My hope, therefore, is that microbiologists and specialists in infectious diseases will find themselves working in parallel to manage both hospital and community infections. There is surely enough for both to do, and other specialists will need support from both services in caring for their particular infection problems. Both services should also be active in providing higher training for future public health doctors.

BARBARA A BANNISTER

Department of Infectious Diseases,

Royal Free Hospital,

London N10 1JN

1 Casewell M. Control of hospital infection. Br Med F 1989;298: 203-4. (28 January.)

Rahman AFMS. Control of hospital infection. Br Med $f$ 1989;298:672-3. (11 March.)

\section{Merit awards}

SIR, - As a consultant in a favoured specialty but an unglamorous district I think I can write without prejudice. Dr Gerald de Lacey again raises the myth that because merit awards are not equally distributed geographically and among specialties the system must be unfair.'

It is well known that competition is such in certain specialties that the appointments committees are always overwhelmed by doctors of talent, whereas in others there may be difficulty in producing an adequate shortlist. This difference also applies to a lesser extent in recruitment 